RAD Conference Proceedings, vol. 3, pp. 6-9, 2018

ISSN 2466-4626 (online) | DOI: 10.21175/RadProc.2018.02

www.rad-proceedings.org

\title{
BIODOSIMETRY AND PHYSICAL DOSIMETRY TOOLS IN RADIATION EXPOSURE ASSESSMENT
}

\author{
Aleksandar P.S. Milovanovićć,2, Jelena Pajić1 ${ }^{*}$, Dubravka Jovičić3 \\ ${ }^{1}$ Serbian Institute of Occupational Health “Dr Dragomir Karajović”, Belgrade, Serbia \\ ${ }^{2}$ School of Medicine, University of Belgrade, Occupational Health Department, Belgrade, Serbia \\ 3 Faculty of Applied Ecology "Futura”, Belgrade, Serbia
}

\begin{abstract}
Occupational exposure to ionizing radiation (IR) involves operations with unsealed or sealed sources. Nuclear medicine staff using unsealed sources is of particular interest for dosimetry research because they are exposed to extremely inhomogeneous fields of ionizing radiation with an increased risk of internal contamination. The findings for two technicians who were unintentionally exposed to IR while operating unsealed sources in the Nuclear Medicine Department are presented here. Exposure evaluation was conducted at the Radiation Protection Center of the Serbian Institute of Occupational Health (SIOH). Values for the personal dose equivalent at a body depth of $10 \mathrm{~mm}$ at the point of application of the personal dosimeter [Hp(10)], the dose equivalent at a body depth $0.07 \mathrm{~mm}$ at the application point of the personal dosimeter [Hp(o.07)], and the results for chromosomal aberrations (CA) and micronuclei (MN) analysis after the first and control examinations at the Cytogenetic Laboratory (SIOH) are presented. The case report for Technician 1 (T1) is an example of agreement between the findings obtained by physical dosimetry and cytogenetic analysis in detecting unintentional exposure and internal contamination with high doses of radionuclides. The results also show that the cytokinesis block micronucleus (CBMN) test is a more sensitive technique in detecting internal contamination than $C A$ analysis. Multiple $M N$ are an unequivocal indicator of genetic damage. Since radiation is a strong inducer of $M N$, these genetic changes may be a certain biomarker of internal contamination.
\end{abstract}

Key words: Radionuclides, internal contamination, biodosimetry, physical dosimetry

\section{INTRODUCTION}

Occupational exposure to ionizing radiation (IR) involves operations with unsealed or sealed sources. In radiation protection, many biological and physical dosimetry techniques have been established to estimate personal or organ dose equivalent and the effective dose.

Nuclear medicine workers operating unsealed sources are of particular interest for bio- and physical dosimetry research, because of exposure to extremely inhomogeneous fields of ionizing radiation and an increased risk of internal contamination. In addition to external exposure, personnel who work with unsealed radiation sources may also be exposed to radioactive material taken into the body, as it may accumulate in specific organs and emit radiation that is absorbed by the surrounding body tissues. Internal doses received by the organs or whole body can be significant for even small intakes of radioactive material [1].

In physical dosimetry, whole or partial body counters, or measurement of activity in biological samples, such as urine, feces etc., are methods of choice for estimation of internal contamination dose [1]. These techniques are generally only qualitative and their use for dose assessment yields uncertain results [1].

The Serbian Institute of Occupational Health (SIOH) maintains laboratories equipped for external dose assessment of personnel exposed to IR. In its cytogenetics laboratory, CA assay (dicentric test) and Cytokinesis-block micronucleus (CBMN) test are performed. The laboratory for personal dosimetry prepares and processes personal dosimeters by the method of thermoluminescent dosimetry. The results reported here involve values for personal dose equivalent at a body depth of $10 \mathrm{~mm}$ at the point of application of the personal dosimeter $[\mathrm{Hp}(10)]$, the dose equivalent at a body depth $0.07 \mathrm{~mm}$ at the application point of the personal dosimeter [Hp(0.07)], and findings concerning chromosomal aberration (CA) and micronuclei (MN) analyses after the first and follow-up examinations in the cytogenetics laboratory for the two technicians who had safety incidents while operating unsealed sources in the Nuclear Medicine Department (NMD).

\section{MATERIALS AND METHODS}

Personal dosimeters were used for the estimation of the exposure. The doses of ionizing radiation absorbed

*jelena.pajic@institutkarajovic.rs 
A. Milovanovic et al., Bio- and physical dosimetry in exposure assessment, RAD Conf. Proc., vol. 3, 2018, 6-9

by the subjects' bodies were measured with thermoluminescent dosimeters (TLD) once a month during the occupational exposure (OE) and expressed in $\mathrm{mSv}$. Routine personal dosimetry was performed using an automatic TLD reader.

The cytogenetic assays were performed according to standard protocols [2].

Detailed information on the occupational and medical history of the two subjects was obtained by the completion of a targeted questionnaire including demographic data, smoking history, alcohol intake, the use of medication, and the duration of exposure to radiation or chemicals.

\section{RESULTS}

More than 50 personal dosimeters belonging to staff from the NMD were processed. Unusual results were obtained only for two technicians. The $[\mathrm{Hp}(10)]$ values were $0.37 \mathrm{mSv}$ and $0.25 \mathrm{mSv}$ and [Hp(0.07)] values were $9.7 \mathrm{mSv}$ and $5.9 \mathrm{mSv}$ for technicians $\mathrm{T} 1$ and $\mathrm{T} 2$, respectively. The difference between the two personal dose equivalents indicated the presence of a high activity beta emitter. Other options (reading errors, dosimeter contamination, etc.) were checked and eliminated.

It was clear that the NMD started with high activity ${ }^{\circ} \mathrm{Y}$ therapy. In an official report from the SIOH, the NMD was warned to stop working without proper protective equipment, and they agreed. However, ${ }^{90} \mathrm{Y}$ therapy was repeated two months later under the same conditions, again without proper protective equipment. The results for the same two technicians are presented in Table 1.

Table 1. Personal dose equivalents

\begin{tabular}{c|l|l|l|l|l}
\multirow{2}{*}{ Worker } & \multirow{2}{*}{$\begin{array}{c}\text { Personal } \\
\text { dose } \\
\text { equivalent }\end{array}$} & \multicolumn{2}{|c|}{ First time } & \multicolumn{2}{c}{ Second time } \\
\cline { 3 - 6 } & Barcode & $\begin{array}{c}\text { Dose } \\
\text { (mSv) }\end{array}$ & Barcode & $\begin{array}{c}\text { Dose } \\
\text { (mSv) }\end{array}$ \\
\hline \multirow{2}{*}{ T1 } & Hp(10) & $658(\mathrm{ii})$ & 0.37 & $6938(\mathrm{ii})$ & 28.9 \\
\cline { 2 - 6 } & $\mathrm{Hp}(0.07)$ & $658(\mathrm{iii})$ & 9.7 & $6938(\mathrm{iii})$ & $1452 ! ! !$ \\
\hline \multirow{2}{*}{$\mathrm{T} 2$} & $\mathrm{Hp}(10)$ & $6405(\mathrm{ii})$ & 0.25 & $10542(\mathrm{ii})$ & 0.42 \\
\cline { 2 - 6 } & $\mathrm{Hp}(0.07)$ & $6405(\mathrm{iii})$ & 5.9 & $10542(\mathrm{iii})$ & 5.2
\end{tabular}

Upon determining that workers were again exposed to unacceptable levels of IR, the SIOH issued a second report, warning the NMD of the dangers associated with administering the ${ }^{\circ} \mathrm{Y}$ therapy without the proper exposure control methods. After receiving the second report, the NMD agreed that the therapy without measures for protection must be discontinued because of the increased risk involved.

The explanation given by the technician revealed that an unshielded syringe with $9^{\circ} \mathrm{Y}$ was carried by hand, close to the technician's body and personal dosimeter while walking from the place of extraction to the application room. That also means that $\mathrm{Hp}(10)=28.9 \mathrm{mSv}$ represents the equivalent dose for the small region near the dosimeter, not for the whole body. The laboratory for personal dosimetry made a cold reconstruction (without the radionuclide), analyzed the whole process and estimated that the contact of the worker's fingers with the unshielded syringe lasted for about $1 \mathrm{~min}$ per patient. Average activity in the syringe was $3 \mathrm{GBq}$. The calculated finger skin dose at the contact point was $2 \mathrm{~Sv}$ per patient [3]. The laboratory estimated, from written data, that each technician administered not less than $10{ }^{90} \mathrm{Y}$ therapy doses of $3 \mathrm{GBq}$ in 8 months' period.

Technician 1 (T1) was examined in the cytogenetics laboratory immediately after the first unusual physical dosimetry finding. CA analysis showed one acentric fragment (ACF) per 200 metaphases, as well as $40 \mathrm{MN}$ per 1000 examined binucleated lymphocytes (BN). According to the HUMN project [4] and other research referring to the general population, average values of $\mathrm{MN}$ are between 7 and 10 per $1000 \mathrm{BN}$ cells [5]. Nucleoplasmic bridges (NPB) and nuclear buds (NB) were also examined. According to the latest Protocols [5], normal values in optimal conditions are: 0-10 NPBs per $1000 \mathrm{BN}$ cells and 0-5 NBs per $1000 \mathrm{BN}$ cells. Fourteen NPBs per 1000 cells were counted. In one BN cell, two NPBs between two main nuclei were found, and twelve BN cells contained one NPB. Ten NBs were found in six BN cells (of 1000 examined); three NBs in one cell, two NBs on the main nuclei in two cells and one NB in three cells.

After this examination, T1 continued working in the NMD with radionuclides, and submitted to a control examination to the cytogenetics laboratory after 4 months. The results of CA analysis were one ACF and one chromatid break $(\mathrm{Bq})$ in two separate metaphases per 200 examined. The MN test showed $37 \mathrm{MN}$ per 1000 BN cells, while 14 NPBs and 9 NBs per 1000 BN cells were also counted.

As a result of the control examination findings, T1 was excluded from working with radiopharmaceuticals for a 3-month period. Next time, CA analysis showed a normal finding, without unstable structural CA, chromatid or isochromatid breaks. However, $19 \mathrm{MN}$ per $1000 \mathrm{BN}$ cells were found. A slight decrease in NPBs and NBs was observed compared to the previous analysis as ten NPBs and six NBs were counted per $1000 \mathrm{BN}$ cells.

Both technicians were non-smokers. T1 had been working in the NMD with radiopharmaceuticals for 20 and T2 for 18 years.

Regarding risk assessment for T1, it is important to mention that the worker had a previous safety incident 7 years ago. The worker spilled ${ }^{131}$ I over the hands. The incident was not reported and no dose estimation was made. The first read-out of the personal dosimeter after the exposure incident occurred 2 weeks later and gave $H p(10)=11 \mathrm{mSv}$. Next month the $H p(10)$ result was $7 \mathrm{mSv}$. The contaminated technician had irradiated the personal dosimeter.

This technician was examined cytogenetically shortly after the safety incident. CA analysis showed one dicentric chromosome (DC) with accompanying $\mathrm{ACF}$ and one isochromatid break (Bq) in two out of 200 examined metaphase cells and $38 \mathrm{MN}$ per 1000 $\mathrm{BN}$ cells. The distribution of $\mathrm{MN}$ was: two cells containing four $\mathrm{MN}$, three cells containing three $\mathrm{MN}$, four cells containing two $\mathrm{MN}$ and thirteen cells containing one MN. NPBs and NBs were not analyzed. 
A. Milovanovic et al., Bio- and physical dosimetry in exposure assessment, RAD Conf. Proc., vol. 3, 2018, 6-9

T1 came to annual control examinations regularly in the period between the two incidents and the findings were within the reference range for the CA analysis (with a small percentage of unstable aberrations), but $\mathrm{MN}$ values were permanently between 16-25 per $1000 \mathrm{BN}$ cells.

Technician T2 underwent cytogenetic examinations in four subsequent years. When the first incident was reported for $\mathrm{T} 1$, technician $\mathrm{T} 2$ had a normal karyotype with no unstable structural $\mathrm{CA}$ or chromosome and chromatid breaks. The MN test also showed values in the reference range ( $11 \mathrm{MN}$ per $1000 \mathrm{BN}$ cells). In the following years, unstable aberrations were absent and $\mathrm{MN}$ test values of 13 and $14 \mathrm{MN}$ per $1000 \mathrm{BN}$ cells, respectively, were in the reference range. However, almost a year after the unintentional exposure to ${ }^{\circ} \mathrm{Y}$, there were two acentric fragments and one chromatid break per 200 analyzed metaphase spreads, and there was also an increased number of $\mathrm{MN}$ in comparison to the values for earlier years. Technician 2 continuously worked with radiopharmaceuticals between the unintentional exposure and the cytogenetic examination next year, which explains the persistence of unstable $\mathrm{CA}$ and an increased number of $\mathrm{MN}$ in metaphases and BN cells.

Results of cytogenetic analyses for both technitians are presented in Figure 1 and Table 2.

Table 2. Results of cytogenetic analysis for $\mathrm{T}_{1}$ and $\mathrm{T}_{2}$

\begin{tabular}{|c|c|c|c|c|c|}
\hline Date & $C A^{a} T 1 / T 2$ & $\begin{array}{l}M N t^{b} \\
T 1 / T 2\end{array}$ & $\begin{array}{c}M N \\
\text { distributionc }^{c} \\
T 1 / T 2 \\
\end{array}$ & $\left|\begin{array}{l}N P B s^{d} \\
T 1 / T 2\end{array}\right|$ & $\begin{array}{l}N B s^{e} \\
T 1 / T 2\end{array}$ \\
\hline $\begin{array}{c}\text { Dec } \\
2001\end{array}$ & $\begin{array}{c}1 \mathrm{DC}+ \\
1 \mathrm{ACF} / \mathrm{NA}\end{array}$ & $38 / \mathrm{NA}$ & $\begin{array}{l}2 \times 4 ; 3 \times 3 ; \\
4 \times 2 ; 13 \times 1\end{array}$ & l & l \\
\hline $\begin{array}{l}\text { Nov } \\
2002\end{array}$ & $\begin{array}{c}1 \mathrm{DC}+ \\
1 \mathrm{ACF} / \mathrm{o}\end{array}$ & $21 / 11$ & $\begin{array}{c}2 \times 3 ; 4 \times 2 ; \\
7 \times 1 / 1 \times 2 ; 9 \times 1\end{array}$ & / & / \\
\hline $\begin{array}{l}\text { May } \\
2003\end{array}$ & $1 \mathrm{ACF} / \mathrm{o}$ & $19 / 13$ & $\begin{array}{c}1 \times 3 ; 4 \times 2 \\
8 \times 1 / 2 \times 2 \\
9 \times 1 \\
\end{array}$ & I & ' \\
\hline $\begin{array}{l}\text { June } \\
2005\end{array}$ & $1 \mathrm{ACF} / \mathrm{NA}$ & $16 / \mathrm{NA}$ & $\begin{array}{c}3 \times 2 ; \\
10 \times 1 / \mathrm{NA}\end{array}$ & / & l \\
\hline $\begin{array}{c}\text { Nov200 } \\
5 \\
\end{array}$ & $\mathrm{o} / \mathrm{NA}$ & $14 / \mathrm{NA}$ & $\begin{array}{c}2 \times 2 ; \\
10 \times 1 / N A\end{array}$ & / & / \\
\hline $\begin{array}{l}\text { June } \\
2006\end{array}$ & $1 \mathrm{ACF} / \mathrm{NA}$ & $16 / \mathrm{NA}$ & $4 \times 2 ; 8 \times 1 / \mathrm{NA}$ & l & l \\
\hline $\begin{array}{l}\text { June } \\
2007\end{array}$ & $1 \mathrm{ACF} / \mathrm{NA}$ & $18 / \mathrm{NA}$ & $\begin{array}{c}1 \times 3 ; 2 \times 2 ; \\
11 \times 1 \\
\end{array}$ & / & l \\
\hline $\begin{array}{c}\text { Jan } \\
2008\end{array}$ & $1 \mathrm{ACF} / \mathrm{NA}$ & $40 / \mathrm{NA}$ & $\begin{array}{c}2 \times 4 ; 4 \times 3 \\
6 \times 2 ; 8 \times 1 / \mathrm{NA}\end{array}$ & $14 / \mathrm{NA}$ & $10 / \mathrm{NA}$ \\
\hline $\begin{array}{l}\text { May } \\
2008\end{array}$ & $1 \mathrm{ACF} / \mathrm{NA}$ & $37 / \mathrm{NA}$ & $\begin{array}{c}1 \times 4 ; 4 \times 3 ; \\
3 \times 2 ; \\
15 \times 1 / \mathrm{NA} \\
\end{array}$ & $\begin{array}{l}14 / \\
\text { NA }\end{array}$ & 9/ NA \\
\hline $\begin{array}{l}\text { Nov } \\
2008\end{array}$ & $\begin{array}{l}1 \mathrm{ACF} / 2 \\
\mathrm{ACF} \text { (in } \\
2 \text { cells) }\end{array}$ & $22 / 19$ & $\begin{array}{c}2 \times 3 ; 3 \times 2 ; \\
10 \times 1 / 3 \times 2 \\
13 \times 1 \\
\end{array}$ & $10 / 9$ & $6 / 8$ \\
\hline $\begin{array}{l}\text { June } \\
2010\end{array}$ & $\mathrm{o} / \mathrm{NA}$ & $13 / \mathrm{NA}$ & $2 \times 2 ; 9 \times 1 / \mathrm{NA}$ & 7/NA & 4/NA \\
\hline
\end{tabular}

a CA: chromosomal aberration analysis; bMNt: total number of MN per 1000 BN cells; cMN distribution :No of cells x No with MN; dNPBs: Nucleoplasmic bridges; eNBs: Nuclear buds; fNA-not analyzed

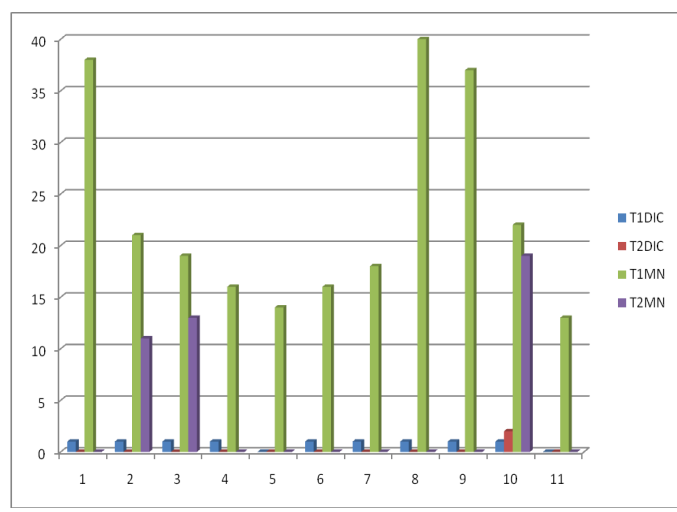

Figure 1. Cytogenetic data for $\mathrm{T}_{1}$ and $\mathrm{T}_{2}$

\section{Discussion}

The case report for $\mathrm{T} 1$ is a very good example of the agreement between the results obtained by physical dosimetry and cytogenetic analysis for the detection of workplace exposure and internal contamination with high doses of radionuclides. In contrast, the disagreement between the results of physical and biodosimetry is often present concerning the exposure to low doses of ionizing radiation $[6,7]$. Namely, a special problem in the radiation protection field is controversial findings about the influence of low doses of IR and exposure duration on the incidence of CAs. There is often a disagreement in dose assessment between physical and biodosimetry after exposure to low doses of IR. Some results indicated an increased frequency of CA after such exposure [6, 8], but others [7] did not find any correlation between the CA frequency and the duration of employment in a controlled workplace.

The use of proper cytogenetic analysis in cases of internal contamination depends on the point of entry and metabolism of radionuclides, although these techniques are generally only qualitative and their use for dose assessment is highly uncertain [1]. According to some researchers [9], the MN test should be used rather than the CA analysis due to increased sensitivity and applicability for different types of internal contamination.

The results also showed that the CBMN test is a more sensitive technique than the $\mathrm{CA}$ analysis for the detection of internal contamination. The CBMN assay is interesting because it allows monitoring of $\mathrm{MN}$ distribution in cells and among cells, the number of NPBs and NBs, as well as apoptotic and necrotic cells [5].

$\mathrm{MN}$ are distributed in $\mathrm{BN}$ cells in a special manner (multiple $\mathrm{MN}$ ), which represents a biological response to irradiation by alpha and beta emitters. In cases of irradiation with high linear energy transfer (LET) particles (like alpha and beta particles), the ionization tracks will be non-randomly distributed between cells, with energy deposited in discrete packets. The number of tracks will be much lower than with low LET radiation at equivalent doses. The result is a nonrandom distribution of induced aberrations. Namely, 
A. Milovanovic et al., Bio- and physical dosimetry in exposure assessment, RAD Conf. Proc., vol. 3, 2018, 6-9

at any observed mean aberration frequency; there will be more cells with multiple aberrations [2].

Multiple $\mathrm{MN}$ is an unequivocal indicator of genetic damage. Since radiation is a strong inducer of $\mathrm{MN}$, multiple $\mathrm{MN}$ found in bladder cells could be a certain biomarker of internal contamination.

It is well known that NPBs are indicators of DC in cells [5], which they cannot distribute in daughter cells during the cell division process, and NB are direct indicators of the amplification of certain genes [5].

Differences between the two technicians regarding their biological response to the same type of internal contamination can be explained by individual variability, and, perhaps, by the fact that $\mathrm{T} 1 \mathrm{had}$ previously been contaminated with another radionuclide seven years before the second exposure incident. T1's greater second response may be explained by a cumulative effect of ionizing radiation from the first incident and chronic exposure to radionuclides in the workplace, which can be seen in the persistence of unstable aberrations and chromosome and chromatid breaks in metaphases in all control examinations in the years between the two incidents.

\section{CONCLUSION}

This case report showed that, in certain situations, even TL dosimetry, as a physical method, and CA and CBMN tests, as biodosimetry methods, are sufficient for the detection of internal contamination and the radiation exposure incident. If TLD holders are filtered properly, it is possible to detect very high beta activity important for nuclear medicine therapy. However, the accurate dose assessment in such situations involves other methods.

The most important conditions for a better practice in nuclear medicine are the use of adequate protection equipment, regular medical and cytogenetic monitoring and education of workers operating unsealed sources of ionizing radiation.

\section{REFERENCES}

1. Practical Radiation Technical Manual, Individual Monitoring, IAEA-PRTM-2, IAEA, Vienna, Austria, 2004.

Retrieved from: https://wwwpub.iaea.org/MTCD/Publications/PDF/PRTM2r1_web.pdf;

Retrieved on: Aug. 10, 2018

2. Cytogenetic Dosimetry: Applications in Preparedness for and Response to Radiation Emergencies, EPR-Biodosimetry 2011, IAEA, WHO, Vienna, Austria, 2011, pp. 173 - 193.

Retrieved from: https://wwwpub.iaea.org/MTCD/publications/PDF/EPR-

Biodosimetry\%202011 web.pdf; Retrieved on: Aug. 10, 2018

3. D. Delacroix et al., "Radionuclide and Radiation Protection Data Handbook 2002," Rad. Prot. Dosimetry, vol. 98, no. 1, pp. 9 - 168, Jan. 2002. DOI: 10.1093/oxfordjournals.rpd.a006705

4. M. Fenech, S. Bonassi, "The effect of age, gender, diet and lifestyle on DNA damage measured using micronucleus frequency in human peripheral blood lymphocytes," Mutagenesis, vol. 26, no. 1, pp. 43 49, Jan. 2011.

DOI: $10.1093 /$ mutage/geqo5o

PMid: 21164181

5. M. Fenech, "Cytokinesis-block micronucleus cytome assay. Protocol," Nature Protocols, vol. 2, pp. 1084 1104, May 2007.

DOI: $10.1038 /$ nprot.2007.77

PMid: 17546000

6. S. Bonassi, "Chromosomal aberrations in lymphocytes predict human cancer independently of exposure to carcinogens," Cancer. Res. vol. 60, no. 6, pp. 1619 - 1625, Mar. 2000.

Retrieved from: http://cancerres.aacrjournals.org/co ntent/6o/6/1619.full-text.pdf; Retrieved on: Aug. 10, 2018

7. A. N. Jha, T. Sharma, "Enhanced frequency of chromosomal aberrations in workers occupationally exposed to diagnostic x-rays," Mutat. Res. vol. 260, no. 4 , pp. $343-348$, Dec. 1991. DOI: 10.1016/0165-1218(91)90020-M

8. D. Jovicic et al., "Detection of premature segregation of centromeres in persons exposed to ionizing radiation," Health. Phys., vol. 98, no. 5, pp. $717-727$ Jun. 2010.

DOI: 10.1097/HP.obo13e3181d26da1 PMid: 20386201

9. G. Joksic, "Cytogenetic tests in the diagnosis of internal contamination with radionuclides," Chem Ind., vol. 55 pp. 273 - 276, May 2001. 